\title{
Cardiovascular collapse due to wild honey Intoxication: A case report
}

\author{
BD Aryal ${ }^{1}$, S Niraula ${ }^{1}$, GB Malla ${ }^{1}$, S Niraula ${ }^{2}$ \\ Department of General Practice and Emergency, BPKIHS, Dharan, Nepal ${ }^{1}$, \\ Institutes of Applied Health Sciences, USTC, Bangladesh ${ }^{2}$
}

\begin{abstract}
Background: Wild honey has been traditionally been used by indigenous people for its medicinal, aphrodisiac and hallucinogenic properties in Nepal and some other countries. Wild (mad) honey intoxication is one of the rarest presentations to emergency department and is caused by ingestion of wild honey obtained from the nectar of Rhododendron species on the higher altitudes. The cause of mad honey poisoning is the toxin grayanotoxin, found in such wild honey. It can also be caused by consuming the leaves, flowers of Rhododendron from Himalayan belt.

Wild honey intoxication has widely been reported from Turkey and the regions around the Black Sea. Some cases have been reported in the few hospitals in Kathmandu and Chitwan. However, such cases have rarely been reported in eastern Nepal. The intoxication might present with mild symptoms of gastrointestinal, cardiovascular and neurological systems or might also present in rare life threatening form with AV block and cardiovascular collapse. Here, we report a case of a seventy three years old man who presented to our emergency department with cardiovascular collapse in the form of severe bradycardia, AV block and hypotension after wild honey consumption.
\end{abstract}

Key words: AV block, cardiotoxicity, grayanotoxin, Nepal, wild (mad) honey

\section{Introduction}

A 73-year-old man of Rai ethnicity was presented in emergency department with the history of sudden onset of multiple episode of vomiting and dizziness (black out), generalized consuming of around $30-40 \mathrm{ml}$ of

\section{Address for correspondence}

Bijaya Devi Aryal

Department of GP \& EM

B.P. Koirala Institute of Health Sciences, Dharan wild honey. While taking detail history, we acknowledged that all these symptoms appeared after weakness after half and hour of ingesting wild honey brought from Taplejung, a Himalayan district of Nepal and was brought immediately to the hospital. There was no history of consumption of any alcohol or drugs, or any other chronic illness. On examination he was not oriented to time, 
place and person. Regarding vital signs, his blood pressure was not recordable, heart rate was $36 / \mathrm{min}$ and irregular, temperature was $97.8^{\circ} \mathrm{F}$ and respiratory rate was $12 / \mathrm{min}$. immediate resuscitation was done with Normal Saline. A 12- lead ECG showed Mobitz type I second degree AV block (Wenckebach phenomenon), with $36 / \mathrm{min}$ of ventricular rate, which is shown below. CK total and CK-MB was within normal limit while Troponin I was negative. Serum potassium concentration was slightly low $(2.9 \mathrm{mmol} / \mathrm{L})$ (probably due to multiple episodes of vomiting) and lactate level was $2 \mathrm{mmol} / \mathrm{L}$, where as all other parameters were normal.

Simultaneously while resuscitating the patient with normal saline, he was given inj. Atropine
$1 \mathrm{mg}$ intravenously immediately after his arrival and after 5 minutes of the $1^{\text {st }}$ dose. He was also given $0.5 \mathrm{mg}$ of inj. Adrenaline intramuscular. After administering two liters of normal saline, his blood pressure rose up to $100 / 60 \mathrm{~mm}$ of $\mathrm{Hg}$, pulse rate was at first 120 /min which then gradually stabilized to 78 /min and patient became responsive to external stimuli. Vasopressor agents were not required to be used in our patient. He was kept under cardiac monitoring in the medicine ward with maintenance fluid and potassium supplementation; and was discharged after 48 hours of observation with normal sinus rhythm and stable vital signs.

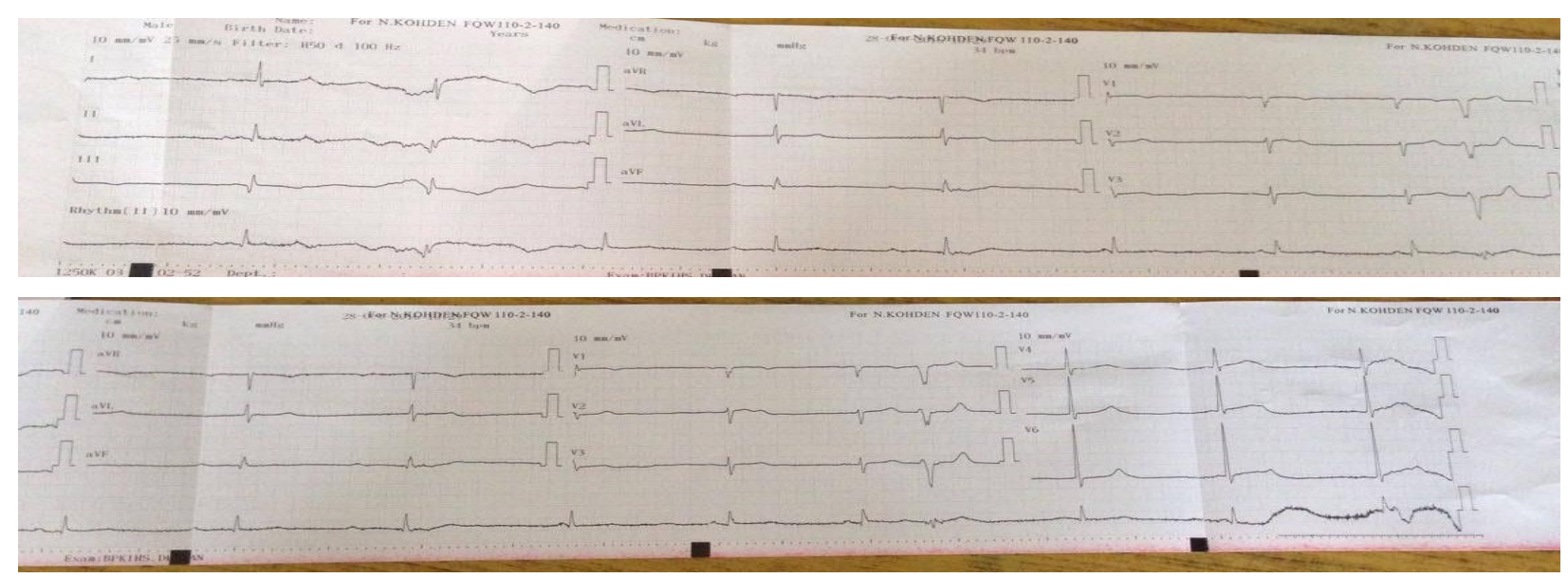

\section{Discussion}

Many people from Turkey, Nepal and other parts of the world consume wild honey as an alternative medicine for the treatment of gastric pains, bowel disorders, and hypertension, and it is also believed to be a sexual stimulant. Toxic effects on body are due to the toxin-grayanotoxin present in such honey which are found in the pollens of rhododendron and spread by wild bees. The 
toxin binds to the receptor site in voltage gated sodium channels within the cell, preventing sodium channel inactivation causing depolarization leading to vagal activation (M2 receptor in myocardium) inducing bradycardia.

The toxic effects of honey poisoning are dose dependent, rarely fatal and generally last for no more than 24 hours. In mild form, dizziness, weakness, excessive perspiration, hypersalivation, nausea, vomiting and paresthesias are present and close follow-up is enough. However, severe intoxication may lead to life threatening cardiac complications such as complete AV block, extreme hypotension and severe bradycardia; and which can be treated with timely recognition of the condition, resuscitation with intravenous fluids, and judicious use of atropine, adrenaline and Vasopressor agents. Sometimes, cardiac pacing may be needed for the resistant cases.

\section{Conclusion}

Clinical features following the ingestion of the wild honey is the basis for the diagnosis. Timely and proper recognition of the condition and appropriate intervention using fluids, atropine and adrenaline can be life-saving in severe intoxications. As honey is a commonly used food in our daily life, more studies are required to explore its potential life threatening effects, their prevention and treatment.

\section{References}

1. A case report of mad honey intoxication, B. Shrestha, P Paudel, Department of Internal medicine; Chitwan Medical College Teaching Hospital 2015 ; 5(12): 40-41. Available online at www.jcmc.cmc.edu.np

2. A. Gunduz, S Turedi, II Uzun and M Tophas, "Mad Honey Poisoning", American journal of Emergency Medicine, 2006;24(5): 595, 598.

3. A.Gunduz, E.S Merice, A Baydin,et al, "Does mad honey poisoning require hospital admission" American Journal of Emergency Medicine, 2009;27(4): 424-427.

4. Shrestha P, Vaidya R, Sherpa K," mad Honey Poisoning", A rare case report of seven cases. Nepal Medical Coll J 2009; 11(3): 2012-2013.

5. Jansen SA, Kleerekooper I, Hoffman ZLM, Kappen IFPM Grayanotoxin poisoning; Mad honey disease and beyond Cardiovascular Toxicology 2012; 12:208-215.

6. Hasen Demir, Arzu Denizbasi and Ozge Onur, Mad Honey Intoxication A case series, Depart of emergency medicine; International scholarly research network; ISRN Toxicology; vol 2011, Article ID526426 